\title{
Correction: Habitual chocolate consumption and risk of cardiovascular disease among healthy men and women
}

Kwok CS, Boekholdt SM, Lentjes MAH, et al. Habitual chocolate consumption and risk of cardiovascular disease among healthy men and women. Heart 2015;101:1279-1287. doi: 10.1136/ heartjnl-2014-307050corr1.

In this paper the paragraph Chocolate consumption in the EPIC-Norfolk cohort contains an error. The section which reads 'Higher chocolate consumption was associated with trends towards a beneficial cardiovascular risk factor profile including lower age, lower BMI, lower waist/hip ratio, lower systolic blood pressure, lower concentrations of apolipoprotein B (apoB) and CRP, a lower prevalence of diabetes mellitus, and more physical inactivity (table 1).' The final sentence should read 'and less physical inactivity (table 1 )'.

C Article author(s) (or their employer(s) unless otherwise stated in the text of the article) 2018. All rights reserved. No commercial use is permitted unless otherwise expressly granted.

Heart 2018;104:532. doi:10.1136/heartjnl-2014-307050corr1

D) Check for updates 